since 2004, and an equivalent picture is seen elsewhere; for example, in Switzerland immigrants now comprise nearly a quarter of the population. We consider here the mental health issues faced by those moving to work in other countries, some of whom aim to become citizens, others to gain temporary economic advantage, and yet others to escape persecution and threats to their personal safety in their countries of origin.

Solvig Ekblad considers the situation in Sweden, where the immigrant population now comprises about $12 \%$ of the total: as she indicates, there have in recent years been several waves of immigration from the 15 republics of the former Soviet Union, and from Eastern Europe, with many women coming in the hope or expectation of marrying Swedish men. Perhaps surprisingly, those from Poland and other Eastern European states are at far higher risk of psychiatric disorder than immigrants from countries that had been Soviet republics, although all are at risk of poorer physical health than the native Swedes. The Swedish system of immigrant management has been criticised by the United Nations for failing to provide adequate support for the physical and mental wellbeing of vulnerable groups.

In the Canadian immigrant population, there is an overrepresentation of those living below the poverty line, as discussed by Stephen Kisely. He, like Dr Ekblad, emphasises the importance of providing adequate support. This includes mental and physical healthcare. As in Sweden, some Canadian provinces do not automatically provide levels of care that are similar to those accessible by the native population. This may be motivated by a desire to discourage those whose reason for coming is to obtain specific treatments for an existing condition. Mental health seems to be better among those who settle in urban areas, for reasons that are at present speculative. There are significant differences in the approach to the management of immigrant health across the Canadian provinces, which have a degree of autonomy in this respect. Manitoba seems to set a high standard, in the opinion of Dr Kisely, to which other provinces might aspire.

Finally, we have an interesting review of research into the psychological adjustment of young refugees, which summarises the findings from a report on the well-being of young asylum seekers, prepared by Winnie Lau and Trang Thomas from Australia. They point out the important fact that nearly half the world's refugees are children and adolescents. Here we have a very different situation to that facing economic migrants, for these people are escaping situations replete with threat and often overt trauma. Drs Lau and Thomas argue that we ought to be aware that many such children may have symptoms that are indicative of post-traumatic stress disorder, although these may not at first be obvious, even to their parents. Fortunately, over time they do seem to adapt to life in their new country, but even so the prevalence of mental health problems in the children of refugees and asylum seekers is much higher than in the indigenous population. We should not only be aware of this situation but, as concerned psychiatrists, we should be pressing for services to be made available to such children in order to facilitate their adjustment and acculturation. There is naturally a greatly enhanced risk to those who migrate unaccompanied by parents, especially boys who were former child soldiers. It seems there are still considerable gaps in our knowledge about the practical solutions to these pressing problems, although we do know that certain governmental policies, such as mandatory detention, are likely to exacerbate them.

\title{
Mental health among recent immigrants to Sweden from Eastern Europe and the former Soviet Union
}

\author{
Solvig Ekblad PhD
}

Associate Professor in Transcultural Psychology, Stress Research Institute, Stockholm University, email Solvig.Ekblad@stressforskning.su.se

\footnotetext{
Ceveral European states such as Sweden have become

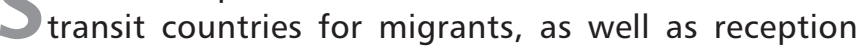
countries for an increasing number of young migrants, not only asylum seekers and refugees from beyond Europe but also from the European Union's new members, after the dissolution of the Soviet bloc in 1989 and then the Soviet Union itself in 1991. Over 110000 immigrants from Eastern Europe and the former Soviet Union resided in Sweden in 2002, although the exact figure is difficult to estimate because of the varied legal status of the migrants. International migration is not a new phenomenon in this part of the world, of course: people have
}

always moved in the search of greater personal safety, among other reasons. However, new groups with new psychosocial needs and demands on the healthcare systems of the host countries will be a challenge. The aim of this article is to give an overview of three sets of empirical data:

$O$ the prevalence of mental disorders among recent immigrants to Sweden from Eastern Europe and the former Soviet Union

their access to mental health and social care facilities arising from their legal status

o their utilisation of health and social services. 


\section{East-west migration}

Earlier waves of migration from east to west were directly connected to political events and human rights issues (for reviews see Fassmann, 1994; Blomstedt et al, 2007). The decision of the Swedish government to allow immigration through the recruitment of workers from Hungary in 1947 and Poland in the mid-1970s has had an impact on immigration from these areas. In addition, there are new waves of immigrants applying for asylum or family union coming from the 15 republics of the former Soviet Union, especially Kazakhstan, Kyrgyzstan, Georgia, Tajikistan, Turkmenistan, Ukraine, Uzbekistan and Belarus (http://www.scb.se).

During the 1990s the number of marriages between Swedish-born men and women from Baltic countries and Russia increased. Indeed, over recent years there has been an overall increase in immigration via marriage to Swedish men (i.e. marriage migration) but the social conditions of these migrant wives in the reception country has received scant attention. In contrast, the Swedish media have, in different ways, paid attention to trafficking from Russia and other Eastern European countries. Skarpsvärd \& Yenidogan (2005), in a qualitative study, interviewed ten Russian women aged from 25 to 50 years who had moved to Norrbotten, in the northern part of Sweden, after marrying Swedish men. They showed that the main motives for migration were economic and social security, a wish to attain the cultural female ideal that the women were unable to realise in their life in Russia, and a vision of a better world in the West. Their self-identity changed as they became more familiar with Swedish society. Further, these women rethought their ideas regarding a woman's position in the family and in society.

\section{Prevalence}

There is a fundamental lack of representative data on the mental health of different groups of migrants (e.g. asylum seekers, refugees, those who migrate for family reasons, undocumented migrants) from Eastern Europe and the former Soviet Union. Non-participation in health surveys is common among these groups. Results from an investigation of a representative postal questionnaire survey performed in Sweden in 1999-2000 showed that immigrants were under-represented; those born in the former Yugoslavia, Arabic-speaking countries and Poland were especially so (Carlsson et al, 2006). In a review (Sungurova et al, 2006), immigrants from Eastern Europe and the former Soviet Union in Sweden were reported to run an increased risk of psychiatric illness, to take psychotropic drugs, to attempt suicide and to complete suicide.

Blomstedt et al (2007) studied a cross-sectional national sample comprising 35459 Swedish-born persons aged 2584 years as well as immigrants from Poland $(n=16)$, other Eastern European countries $(n=164)$ and the former Soviet Union $(n=60)$ who arrived in Sweden after 1944 and were interviewed during 1994-2001. They found that the country of birth had a strong influence on self-reported mental health. Polish and other East European immigrants in general had a twofold higher odds ratio of reporting psychiatric illness and psychosomatic complaints. This result was not accounted for by demographic and socio-economic variables. Immigrants from the former Soviet Union, however, had odds similar to those of the Swedish-born reference group. The conclusion was that adjustments for acculturation variables (e.g. language spoken at home and number of years in Sweden) changed the relationship between the country of birth and the outcomes only to a small amount.

In another cross-sectional study, Sungurova et al (2006) during 1993-2000 interviewed 373 immigrants from Poland and other European countries (Hungary, Bulgaria, Czech Republic, Slovakia and Romania) and from the former Soviet Union (all 15 former republics), aged 25-84 years, who arrived in Sweden after 1944, and compared them with 35711 Swedish counterparts. Age- and gender-adjusted unconditional logistic regression showed in general a $92 \%$ higher risk of reporting poor health among immigrants than among Swedish-born respondents. The risk remained after adjustment for several potential confounders (living singly, having a poor social network, low socio-economic status and smoking) and after an additional adjustment for acculturation (language at home and years in Sweden).

\section{Utilisation of healthcare}

Sweden is one of the few member states of the European Union in which adult asylum seekers and undocumented foreign nationals do not have access to the same healthcare as adults domiciled in Sweden (Nørredam et al, 2006). All asylum seekers who come to Sweden are offered a medical examination free of charge. During last year, only $45 \%$ of the newcomers chose to undergo such an examination (Wintzer, 2008). After a mission to Sweden, Paul Hunt, a special rapporteur on the right of everyone to the enjoyment of the highest attainable standard of physical and mental health, expressed the opinion that such differential treatment constitutes discrimination under international human rights law (Hunt, 2007).

\section{Conclusion}

The results from studies that have been performed in Sweden on the immigrant population are broadly in line with those from other West European countries. In particular, it is possible to identify inequality in health by country of birth. Immigrants are significantly under-represented in such studies (Carlsson et al, 2006). Until now, there have been no causal pathways identified between migration and health among the populations studied. Being born in Eastern Europe or the former Soviet Union is an independent risk factor for reporting poor health. Further, studies have shown that selfreported health is poorer among those from Eastern European countries than it is among those from the former Soviet Union. However, this may largely be explained in terms of differential access to resources and different exposures to risk.

The 'migration import' hypothesis assumes that rates of illness among immigrants correspond more closely to those of their country of origin than to those of their adopted country (Ponizovsky et al, 1999). This effect tends to reduce over time and the rates become more like those of the host population (the 'migration convergence' hypothesis).

There is a consensus that living conditions are related to health in the population. It is important for the primary 
and public healthcare services to pay attention to the health status and needs of immigrants. Kastrup (2008) proposes a competent treatment of patients with multicultural backgrounds, which demands that mental health professionals be aware of alternative traditional approaches and show an interest and an ability to bridge the more traditional and the Western approaches to treatment. Transcultural psychiatry today is recommended to facilitate 'an understanding about basic mental functions and disease categories, while paying specific attention to culturally influenced constellations of stress factors, psychosocial variables that influence treatment outcome and the individual understanding and interpretation of disease symptoms' (Schouler-Ocak et al, 2008, p. S1).

Healthcare and healthcare systems should be seen and understood in their sociocultural context (Kastrup, 2008). Access barriers remain, as does discrimination. As poor mental health may block the process of acculturation, the mental health of immigrants from East European countries should be paid more attention, particularly with the recent enlargement of the European Union.

\section{References}

Blomstedt, Y., Johansson, S.-E. \& Sundquist, J. (2007) Mental health of immigrants from the former Soviet Bloc: a future problem for primary health care in the enlarged European Union? A cross-sectional study. BMC Public Health, 7, 27.
Carlsson, F., Merlo, J., Lindström, M., et al (2006) Representativity of a postal public health questionnaire survey in Sweden, with special reference to ethnic differences in participation. Scandinavian Journal of Public Health, 34, 132-139.

Fassmann, H. (1994) European East-West migration, 1945-1992. International Migration Review, 28, 520-538.

Hunt, P. (2007) Implementation of General Assembly Resolution 60/251 of 15 March 2006 entitled 'Human Rights Council'. Report of the Special Rapporteur on the right of everyone to the enjoyment of the highest attainable standard of physical and mental health. A HRC/4/28/Add.s, 28 February. United Nations.

Kastrup, M. (2008) Staff competence in dealing with traditional approaches. European Psychiatry, 23, S59-S68.

Nørredam, M., Mygind, A. \& Krasnik, A. (2006) Access to health care for asylum seekers in the European Union - a comparative study of country policies. European Journal of Public Health, 16, 286-290.

Ponizovsky, A. M., Ritsner, M. S. \& Modai, I. (1999) Suicidal ideation and suicide attempts among immigrant adolescents from the former Soviet Union to Israel. Journal of the American Academy of Child and Adolescent Psychiatry, 38, 1433-1441.

Schouler-Ocak, M., Haasen, C. \& Heinz, A. (2008) Migration and transcultural psychiatry in Europe. European Psychiatry, 23, S1-S3.

Skarpsvärd, R.-M. \& Yenidogan, J. (2005) Tryggare kan ingen vara...?! Äktenskapsmigrationens drivkrafter. Sociologi C/D-uppsats, report no. 27. Luleå tekniska universitet, Institutionen för Arbetsvetenskap, Avdelningen för Industriell produktionsmiljö.

Sungurova, Y., Johansson, S.-E. \& Sundquist, J. (2006) East-West health divide and East-West migration: self-reported health of immigrants from Eastern Europe and the former Soviet Union in Sweden. Scandinavian Journal of Public Health, 34, 217-221.

Wintzer, S. (2008) Hälsoundersökningar av asylsökande har ökat. Sveriges kommuner och landsting, http://www.skl.se/artikel.asp?C $=6848 \& A=$ 51775 (accessed May 2008).

\section{Migration and mental health in Canada: can government policy help?}

\section{Stephen Kisely}

Chair in Health Outcomes, Department of Psychiatry, Dalhousie University, Halifax, NS, Canada, email Stephen.Kisely@cdha.nshealth.ca

anada admits more than 220000 immigrants every year and this is reflected in the statistic that $18 \%$ of the population was born abroad (Beiser, 2005). However, government policy emphasises the admission of healthy immigrants rather than their subsequent health. Immigrants do not show a consistently elevated rate of psychiatric illness, and morbidity is related to an interaction between predisposition and socio-environmental factors, rather than immigration per se. These factors include forced migration and circumstances after arrival, such as poverty, limited recognition of qualifications, discrimination and isolation from the immigrant's own community. For instance, in Canada more than $30 \%$ of immigrant families live below the official poverty line in the first 10 years of settlement (Beiser, 2005).

Some groups are at higher risk of psychiatric morbidity, such as asylum seekers. In this population, symptoms of depression and anxiety, panic attacks or agoraphobia are common and are often reactions to past experiences and current social circumstances (Kisely et al, 2002). More than $20 \%$ of asylum seekers in Australia reported previous torture, a third reported imprisonment for political reasons, and a similar proportion the murder of family or friends (Silove et al, 2000; Steel \& Silove, 2001; Sultan \& O'Sullivan, 2001). In one British study, $65 \%$ of Iraqi refugees had a history of systematic torture during detention (Gorst-Unsworth \& Goldenburg, 1998). These experiences are compounded by the rigours of reaching safety, social isolation, poverty, hostility and racism (Kisely et al, 2002).

\section{Acculturation}

Although resettlement countries can do little to address presettlement experiences, governments can address issues of unemployment, discrimination and acculturation following 